\title{
RICE AREA ESTIMATION USING PARAMETERIZED CLASSIFICATION OF SENTINEL 1A SAR DATA
}

\author{
Mugilan Govindasamy Raman ${ }^{1, *}$, Ragunath Kaliaperumal², Sellaperumal Pazhanivelan², Balaji Kannan² \\ ${ }^{1}$ Senior Research Fellow, Department of Remote Sensing and GIS, TNAU, Coimbatore -3 \\ ${ }^{2}$ Deparment of Remote Sensing and GIS, TNAU, Coimbatore - 3 \\ *mugilantnau@gmail.com
}

Commission III, WG III/10

KEY WORDS: Sentinel 1A, Rice, Parameterized Classification, Kappa Index

\begin{abstract}
:
A research study was conducted during Rabi 2016 (Samba season) to estimate rice area using SAR data in Tiruvarur district of Tamil Nadu. Multi temporal Sentinel 1A satellite data with VV and VH polarization at $20 \mathrm{~m}$ spatial resolution was acquired between September 2016 and January 2017 at 12 days interval and processed using rule-based Parameterized classification in MAPscapeRICE software. Continuous monitoring for crop parameters and validation exercise was done for accuracy assessment. Spectral dB curve of rice was generated and the $\mathrm{dB}$ values ranged from -12.76 to -9.95 for $\mathrm{VV}$ and from -19.25 to -15.15 for VH polarization with an average primary variation of 1.3 and $2.5 \mathrm{~dB}$ respectively. Start of Season (SOS) map was derived from satellite data showing rice emergence dates for the cropping season. A total rice area of 106773 ha was estimated in Tiruvarur district using VV polarization with an overall accuracy of $79.5 \%$ and 0.59 kappa index, while in VH polarization, the rice area was estimated to be 91007 ha with $82.1 \%$ over all accuracy and 0.64 kappa index. The lesser accuracy in VV polarization was due to underestimate of direct seeded rice area and in VH polarization, it was due to underestimate in Transplanted rice area. The VV and VH rice area maps were then integrated to derive a VV-VH rice area map in MAPscape-RICE software and it recorded a total rice area of 124551 ha with an accuracy of $91.5 \%$ and 0.83 -kappa index
\end{abstract}

\section{Introduction}

Agricultural resources are among the most important renewable, dynamic natural resources. The demand for food, clothes and shelter has been increasing with the ever-increasing population in the country. The need for timely and reliable information on crop area and production for tactical and strategic decision making by all the stakeholders in agriculture, such as producers, processors, resource managers, marketing finance and the government is well known.

With the launch and continuous availability of multi-spectral (visible, near infrared) sensors on polar orbiting earth observation satellites (LANDSAT, SPOT, IRS, etc.) remote sensing (RS) data has become an important tool for area and yield estimation. Remote sensing data provide timely, accurate and objective estimation of crop identification, crop monitoring, acreage and yield estimation. Since the 1980's, optical remote sensing has been widely used to identify various crops, however, optical images are not often available in the key growth period of crops, owing to the cloudy and rainy weather. Thus, it has a negative effect on the accuracy and timeliness of crop area monitoring. As a new technology with an advantage of all weather, all-time, high resolution and wide coverage, Synthetic Aperture Radar (SAR) has been widely applied in agricultural condition monitoring which provides a strong complement and support for crop identification in data and technology aspect. For the past twenty years, tremendous development in SAR application for crop identification has been made. Scientists have tried with combinations of SAR bands and Polarization to identify and estimate crop and acreage. The accuracy of the estimation had been tried with combining multiple sensors of SAR and in combination with the optical sensors. AR data was acquired in single and cross polarization, which has the potential to retrieve different information of the crop simultaneously. The potential of cross polarization in combination with the single polarization was attempted for rice area

\section{METHODOLOGY}

2.1

\section{Study Area}

Tiruvarur district is one of the 32 districts in the Tamil Nadu state of India. The district occupies an area of $2161 \mathrm{~km}^{2}$. It lies between Nagapattinam district on the east and Thanjavur District on the west, and is bounded by the Palk Strait on the south (Fig. 1). Tiruvarur is located at $9.28^{\circ} \mathrm{N}$ and $79.3^{\circ} \mathrm{E}$. Paddy is the major crop while the others being black gram, green gram, groundnut and gingely. Tiruvarur receives an annual rainfall of 1,260 millimeters. It experiences tropical climate during summer from March to May. Paddy is cultivated in three seasons namely Kuruvai (June-August), Samba (AugustJanuary) and Thaladi (January-March). Being an agricultural district, the predominant industries were agriculture based like modern rice milling, palm oil refinery, poultry, livestock and coir based.

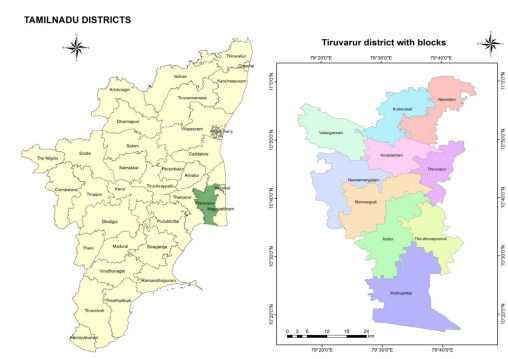

Fig.1 Location Map of Tiruvarur district in Tamil Nadu Satellite Data 
Synthetic Aperture Radar (SAR) has the advantage of operating at wavelengths not impeded by cloud cover or a lack of illumination and can acquire data over a site during day or nighttime under all weather conditions. Sentinel-1A, with its CSAR instrument could offer reliable, repeated wide area monitoring. It is the first Sentinel 1 satellite launched as part of the European Union's Copernicus programme. It provides dual polarization capability, very short revisit times and rapid product delivery. The satellite carries a C-band Synthetic Aperture Radar which will provide images in all light and weather conditions with VV (Vertical-Vertical) and VH (Vertical-Horizontal) polarization and the data obtained at twelve days interval. Sentinel1-A has four standard operational modes, designed for interoperability with other systems. Level1 ground range (GRD) product obtained by interferometric wide (IW) swath mode (1) of High Resolution (HR) was used for this research. The characteristics of IW1-GRD-HR product are given in Table1. In order to have a full coverage during the crop-growing period of rice, the satellite data were downloaded for 19th September 2016 to 17th January 2017 at 12days interval from https://scihub.copernicus.eu/dhus/.

\begin{tabular}{|l|l|}
\hline \multicolumn{1}{|c|}{ Parameters } & Characteristics \\
\hline Pixel value & $\begin{array}{l}\text { Magnitude } \\
\text { detected }\end{array}$ \\
\hline Coordinate system & Ground range \\
\hline Polarization options & $\begin{array}{l}\text { Single(HH or VV) } \\
\text { or Dual (HH+HV } \\
\text { or VV+VH) }\end{array}$ \\
\hline Resolution (range x azimuth in meters) & $20.4 \mathrm{x} 21.7$ \\
\hline $\begin{array}{l}\text { Pixel spacing (range x azimuth in } \\
\text { meters) }\end{array}$ & $10 \mathrm{x} 10$ \\
\hline Incidence angle (degree) & 32.9 \\
\hline Radiometric resolution & $1.7 \mathrm{~dB}$ \\
\hline Ground range coverage & $251.8 \mathrm{~km}$ \\
\hline Absolute location accuracy (m) (NRT) & 7 \\
\hline Equivalent Number of Looks (ENL) & 4.4 \\
\hline Number of looks (range x azimuth) & $5 \mathrm{x} 1$ \\
\hline Range look bandwidth (Hz) & 14.1 \\
\hline Lits per pixel & $0.250,0.000$ \\
\hline
\end{tabular}

Table 1. Characteristics of Sentinel1-A (IW1-GRD-HR) Data (DeZan and Guarnieri., 2006)

\section{$2.2 \quad$ Softwares}

GIS and other software's viz., MAPscape-RICE, ArcGIS, QGIS, ORYZA growth model were used in the study to perform different operations to achieve results.

MAPscape-RICE - SAR data processing and rice area estimation

ArcGIS and QGIS - GIS operations like mapping and statistics deriving.

\subsection{Basic Processing of SAR Data for Multi-Temporal Analysis}

A fully automated processing chain developed by Holecz et al. (2013) used to convert the multi-temporal space-borne SAR SLC data into terrain-geocoded $\sigma^{\circ}$ values. The processing chain is a module within the MAPscape-RICE software. The basic processing chain included the following steps viz., Strip mosaicking, Co-registration, Time-series speckle filtering, Terrain geocoding, radiometric calibration, normalization, Anisotropic non-linear diffusion (ANLD) filtering, Removal of atmospheric attenuation.

\subsection{Multi-Temporal $\sigma^{\circ}$ Rule-Based Rice Detection for retrieving Rice area}

The multi-temporal stack of terrain-geocoded $\sigma^{\circ}$ images was input to a rule-based rice detection algorithm in MAPscapeRICE. The temporal evolution of $\sigma^{\circ}$ was analyzed from an agronomic perspective, which also required a priori knowledge of rice maturity, calendar and duration and crop practices from field information and knowledge of the study location. The temporal signature was frequency and polarization dependent and also relied on the crop establishment method and to some extent on crop maturity. This implied that general rules could be applied to detect rice, but that the parameters for these rules needed to be adapted according to the agro-ecological zone, crop practices and rice calendar. The Rule-based rice detection algorithm for multi-temporal C-band $\sigma^{\circ}$ is presented in Fig.2 with the parameters used in the MAPscape-RICE software.

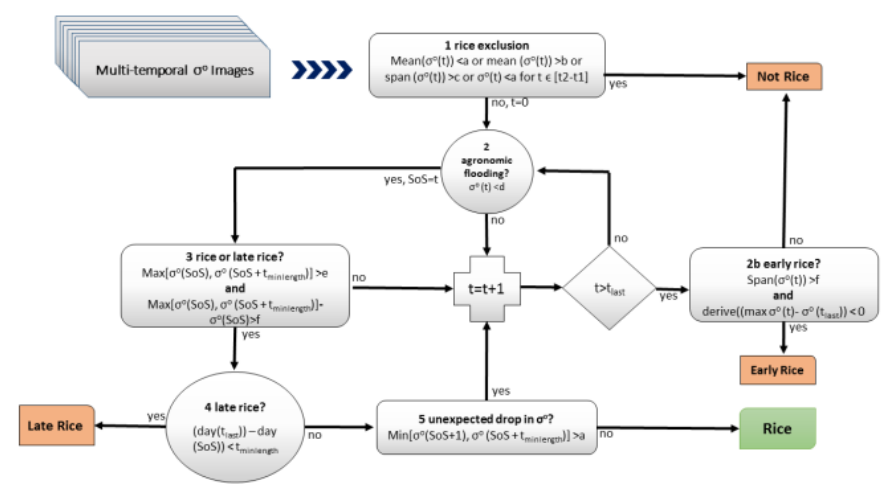

Fig.2 Rule-based rice detection algorithm for multi-temporal C-band $\sigma^{\circ}$ in MAPscape-RICE 
$\mathrm{a}=$ lowest mean

$\mathrm{b}=$ highest mean

$\mathrm{c}=$ maximum variation

$\mathrm{d}=$ maximum value at $\mathrm{SoS}$

$\mathrm{e}=$ minimum value at

maximum peak

$\mathrm{f}=$ minimum variation $\mathrm{t}=$ time

$\mathrm{t}_{2}-\mathrm{t}_{1}=$ maximum time under

water

tmin length $=$ minimum

number of days of season length

tmax length $=$ maximum number of days of season length

$\mathrm{t}_{\text {last }}=$ date of the last

acquisition

SoS $=$ Start of Season

\subsection{Use of Temporal Features to Guide Parameter Selection for the Rule-Based Classifier}

The choice of parameters a, b, c, d, e and $\mathrm{f}$ was guided by a simple statistical analysis of the temporal signature of $\sigma^{\circ}$ values in the monitored fields. The criteria used to guide the selection of parameters. The mean, minimum, maximum and range of $\sigma^{\circ}$ were computed for the temporal signature of each monitored field. Then, we computed the minima and maxima of those mean $\sigma^{\circ}$ values across fields, the maxima of the minimum $\sigma^{\circ}$ values across fields, the minima of the maximum $\sigma^{\circ}$ value across fields and the minimum and maximum of the range of $\sigma^{\circ}$ values across fields (Holecz et al., 2013). These six statistics which we call temporal features concisely characterize the key used to guide the choice of the six parameter values as shown in Table 2.The parameters tmin length, tmax length and $\mathrm{t} 2-\mathrm{t} 1$ were easier to estimate. Tmin length restricted the number of flowering; this value can be set to 40-70 days. Tmaxlength restricts the duration between two $\sigma^{\circ}$ minima in the series and 120 days was a suitable cut-off that would be representative of an intensive triple-rice system (three crops in one year). $\mathrm{t} 2-\mathrm{t} 1$ is the maximum duration of agronomic flooding at the start of the season which could be set to a relatively high value of 40 to 50 to capture even the longest land preparation phases.

\begin{tabular}{|l|l|}
\hline Parameter & $\begin{array}{l}\text { Relationship between Parameter } \\
\text { and Temporal Feature }\end{array}$ \\
\hline $\mathrm{a}=$ lowest mean & $\begin{array}{l}\mathrm{a}<\text { (i) minima of the mean } \sigma^{\circ} \\
\text { across all rice signatures }\end{array}$ \\
\hline $\mathrm{b}=$ highest mean & $\begin{array}{l}\mathrm{b}>\text { (ii) maxima of the mean } \sigma^{\circ} \\
\text { across all rice signatures }\end{array}$ \\
\hline $\begin{array}{l}\mathrm{c}=\text { maximum } \\
\text { variation }\end{array}$ & $\begin{array}{l}\mathrm{c}>\text { (vi) maxima of the range in } \sigma^{\circ} \\
\text { across all rice signatures }\end{array}$ \\
\hline $\begin{array}{l}\mathrm{d}=\text { max value at } \\
\text { SoS }\end{array}$ & $\begin{array}{l}\mathrm{d}>\text { (iii) highest minima in } \sigma^{\circ} \text { across } \\
\text { all rice signatures }\end{array}$ \\
\hline $\begin{array}{l}\mathrm{e}=\text { min value at } \\
\text { peak }\end{array}$ & $\begin{array}{l}\mathrm{e}<\text { (iv) lowest maxima in } \sigma^{\circ} \text { across } \\
\text { all rice signatures }\end{array}$ \\
\hline $\begin{array}{l}\mathrm{f}=\text { minimum } \\
\text { variation }\end{array}$ & $\begin{array}{l}\mathrm{f}<(\mathrm{v}) \text { minima of the range in } \sigma^{\circ} \\
\text { across all rice signatures }\end{array}$ \\
\hline
\end{tabular}

Table. 2 Site-specific parameters for the rule-based classification and the criteria used to select them based on temporal features

\section{Rice area integration (VV and VH Polarization)}

Rice area estimation will be carried out for $\mathrm{VV}$ and $\mathrm{VH}$ polarization data separately using the $\mathrm{dB}$ stacks of the respective polarization. The Rule based classifier will be run separately to derive the rice area. From the outputs of the two runs of $\mathrm{VV}$ and $\mathrm{VH}$ polarization, integration will be carried out

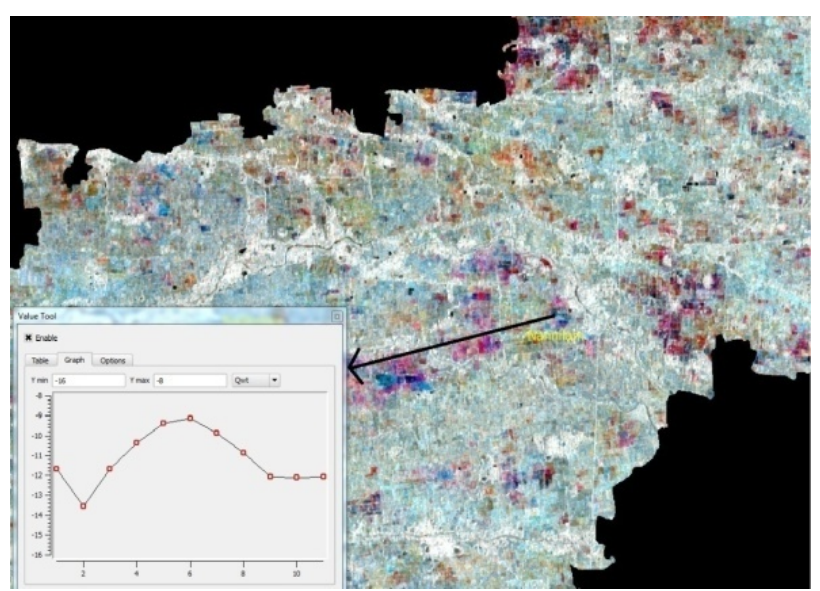

Information in the rice signatures of the observed fields and each one relates directly to one parameter. Hence, the value of the six temporal features from the monitoring locations at each site can be highest $\sigma^{\circ}$ value in the temporal signature. Since Cband $\sigma^{\circ}$ saturates before rice

\section{Accuracy Assessment}

The Error matrix and Kappa statistics are used for evaluating the accuracy of the estimated rice area. The class allocation of each pixel in classified image is compared with the corresponding class allocation on reference data (Ground Truth Data Collection) to determine the classification accuracy. The pixels of agreement and disagreement were compiled in the form of an error matrix, where the rows and columns represent the number of all classes and the elements of matrix represent the number of pixels in the testing dataset. The accuracy measures, such as overall accuracy, producer's accuracy and user's accuracy were estimated from the error matrix (Congalton, 1991). The overall accuracy, which is the percentages of correctly classified cases lying along the diagonal, was determined. Another measure of classification accuracy is the kappa coefficient, which is a measure of the proportional (or percentage) improvement by the classifier over a purely random assignment to classes (Richards, 1993).

\section{RESULTS}

\subsection{Rice area mapping using SAR data}

The multi-temporal stack of terrain-geocoded $\sigma^{\circ}$ images of Sentinel 1A acquired from September, 2016 to January, 2017 was given as input to a rule-based rice detection algorithm in MAPscape-RICE software, which was an proprietary software with the capability of performing sequential SAR data processing. A $\mathrm{dB}$ stack was generated using eleven sets of Sentinel-1A data (Table 3) acquired after basic processing viz., orbital and radiometric correction, geo-coding, mosaicking and speckle filtering. Temporal signatures were extracted in VV and VH polarization for each monitoring field and used to generate the $\mathrm{dB}$ curves for rice fields for both $\mathrm{VV}$ and $\mathrm{VH}$ polarization. The temporal signature for a selected representative pixel in VV and $\mathrm{VH}$ polarization was generated to visualize the resulting rule based classification receptively was presented in Fig.3 


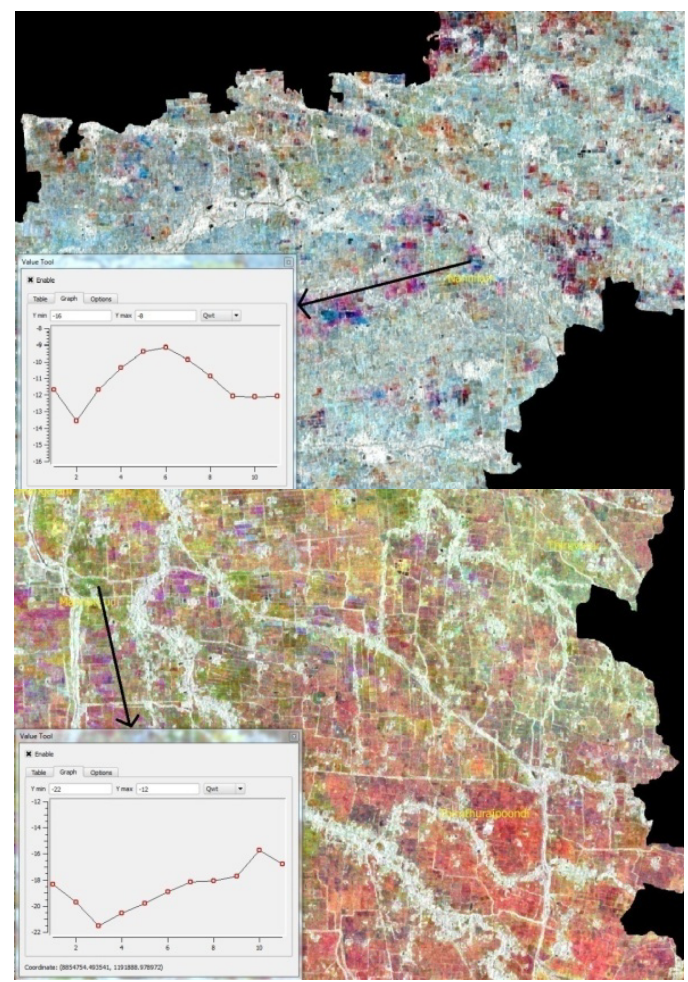

Fig.3. dB stack for VV and VH polarization

A detailed analysis of temporal signatures of rice for both VV and $\mathrm{VH}$ polarization were done separately for deriving parameters used to classify rice pixels in MAPscape-RICE software. The eleven parameters derived from the temporal signatures of $\mathrm{VV}$ and $\mathrm{VH}$ polarization for analysis were, mean value of Built-up area, minimum value at tillering, minimum and maximum crop cycle duration, maximum value at start of season, start of season to last acquisition, minimum primary and secondary variation, maximum value and days of temporary water. The parameters used for classification were given in the Table 4

\begin{tabular}{|l|l|}
\hline S.No & $\begin{array}{l}\text { Date } \\
\text { Acquisition }\end{array}$ \\
\hline $\mathbf{1}$ & 19 Sep 2016 \\
\hline $\mathbf{2}$ & 01 Oct 2016 \\
\hline $\mathbf{3}$ & 13 Oct 2016 \\
\hline $\mathbf{4}$ & 25 Oct 2016 \\
\hline $\mathbf{5}$ & 06 Nov 2016 \\
\hline $\mathbf{6}$ & 18 Nov 2016 \\
\hline
\end{tabular}

\begin{tabular}{|l|l|}
\hline S.No & $\begin{array}{l}\text { Date of } \\
\text { Acquisition }\end{array}$ \\
\hline $\mathbf{7}$ & 30 Nov 2016 \\
\hline $\mathbf{8}$ & 12 Dec 2016 \\
\hline $\mathbf{9}$ & 24 Dec 2016 \\
\hline $\mathbf{1 0}$ & 05 Jan 2017 \\
\hline $\mathbf{1 1}$ & 17 Jan 2017 \\
\hline
\end{tabular}

Table.3 Sentinel 1A data acquisition dates during Samba 2016 for Tiruvarur district

\begin{tabular}{|c|c|c|c|}
\hline S.No & Parameter & $\mathbf{V V}$ & VH \\
\hline 1. & $\begin{array}{l}\text { Mean Value of Water } \\
\text { (dB) }\end{array}$ & -17.00 & -21.00 \\
\hline 2. & $\begin{array}{l}\text { Max Value of } \\
\text { Temporary Water }(\mathrm{dB})\end{array}$ & -15.00 & -22.00 \\
\hline 3. & $\begin{array}{l}\text { Days of Temporary } \\
\text { Water (days) }\end{array}$ & 65 & 65 \\
\hline 4. & $\begin{array}{l}\text { Mean Value of Built up } \\
\text { Areas }(\mathrm{dB})\end{array}$ & -7.00 & -14.00 \\
\hline 5. & $\begin{array}{l}\text { Max Value at Start of } \\
\text { Season }(\mathrm{dB})\end{array}$ & -11.00 & -16.00 \\
\hline 6. & $\begin{array}{lll}\text { Min } & \text { Primary } & \text { Variation } \\
(\mathrm{dB}) & & \end{array}$ & 1.30 & 2.50 \\
\hline 7. & $\begin{array}{l}\text { Min Secondary } \\
\text { Variation }(\mathrm{dB})\end{array}$ & 0.50 & 0.00 \\
\hline 8. & $\begin{array}{l}\text { Min Value at Tillering } \\
(\mathrm{dB})\end{array}$ & -11.50 & -20.00 \\
\hline 9. & $\begin{array}{ll}\text { Minimum } & \text { Cycle } \\
\text { Duration (days) } & \end{array}$ & 60 & 80 \\
\hline 10. & $\begin{array}{ll}\text { Maximum } & \text { Cycle } \\
\text { Duration (days) } & \end{array}$ & 150 & 120 \\
\hline 11 & $\begin{array}{l}\text { SOS to Last Acquisition } \\
\text { (days) }\end{array}$ & 40 & 10 \\
\hline
\end{tabular}

Table.4. Classification parameters used for rice pixel delineation in $\mathrm{VV}$ and $\mathrm{VH}$ polarization data

The start of the season for each pixel. This might be the due to soil moisture variation or sowing which made the soil surface smoother (Karjalainen et al., 2004). The average $\mathrm{dB}$ values curve derived from the selected rice points for both $\mathrm{VV}$ and $\mathrm{VH}$ polarization were shown in the Fig.4

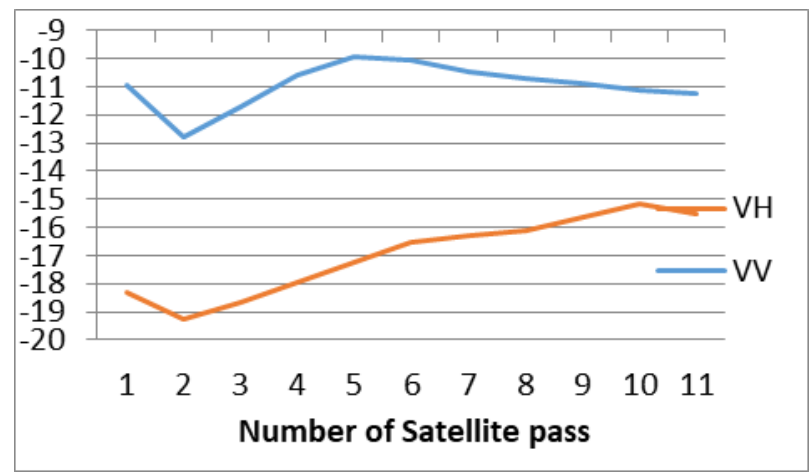

Fig.4. Average $\mathrm{dB}$ value of selected field for $\mathrm{VV}$ and $\mathrm{VH}$ polarization 
Both the $\mathrm{VV}$ and $\mathrm{VH}$ polarization signatures showed a minimum $\mathrm{dB}$ value at agronomic flooding and a peak at maximum tillering stage. At flooding, minimum $\mathrm{dB}$ value from -13.64 to -12.18 was recorded with an average of -12.55 and the average maximum value at peak tillering stage was found to be -10.47 with a range of -8.67 to -11.41 in VV polarization, where as in $\mathrm{VH}$ polarization at flooding the minimum $\mathrm{dB}$ value ranged from-19.56to -18.79 with an average of -19.23. At peak tillering stage in $\mathrm{VH}$ polarization average was found to be -16.35 with a range of -15.77 to -16.92 across Tiruvarur district. Rice crop shows significant temporal behavior and a large dynamic range $(-14.4$ to $-8.41 \mathrm{~dB})$ during its growth period. The Minimum primary variation was found to be 1.3 and $2.5 \mathrm{~dB}$ corresponding to growth at vegetative and maximum tillering stage in $\mathrm{VV}$ and VH polarization respectively. The lowest values at emerging were due to less back scattering from less vegetation cover with rougher surface, which was the moment to capture the start of the season for each pixel. This might be the due to soil moisture variation or sowing which made the soil surface smoother (Karjalainen et al., 2004). The average $\mathrm{dB}$ values

\subsection{Rice Area and Accuracy assessment}

The methodology involved collection of ground truth for rice growing points and analyzing the temporal signature and deriving of parameters to train the software in classifying the rice pixels. Two sets of $\mathrm{dB}$ stacks consisting of eleven temporal scenes of Sentinel 1A SAR data for VV polarization and VH polarization respectively were given input in the "Single Season Cultivated Area and Seasonal Dynamics" module of MAPscape-RICE software for deriving the Rice maps separately for VV and VH Polarization. The parameters derived from the temporal signatures of rice for $\mathrm{VV}$ and $\mathrm{VH}$ were used respectively with the above module. The outputs from the module run were then subjected for validation with ground truth data.

The VV and VH rice area maps were then integrated to derive a VV-VH rice area map using the module "Rice area mosaic" of MAPscape-RICE software. The derived integrated map was also validated with ground truth data. The rice map generated contains two groups viz., Late Rice and Rice, which were combined into one class to get the total rice area. The Rice area Map of $\mathrm{VV}, \mathrm{VH}$ and Integrated $\mathrm{VV}-\mathrm{VH}$ polarization were presented below in the Fig. 5-7 respectively

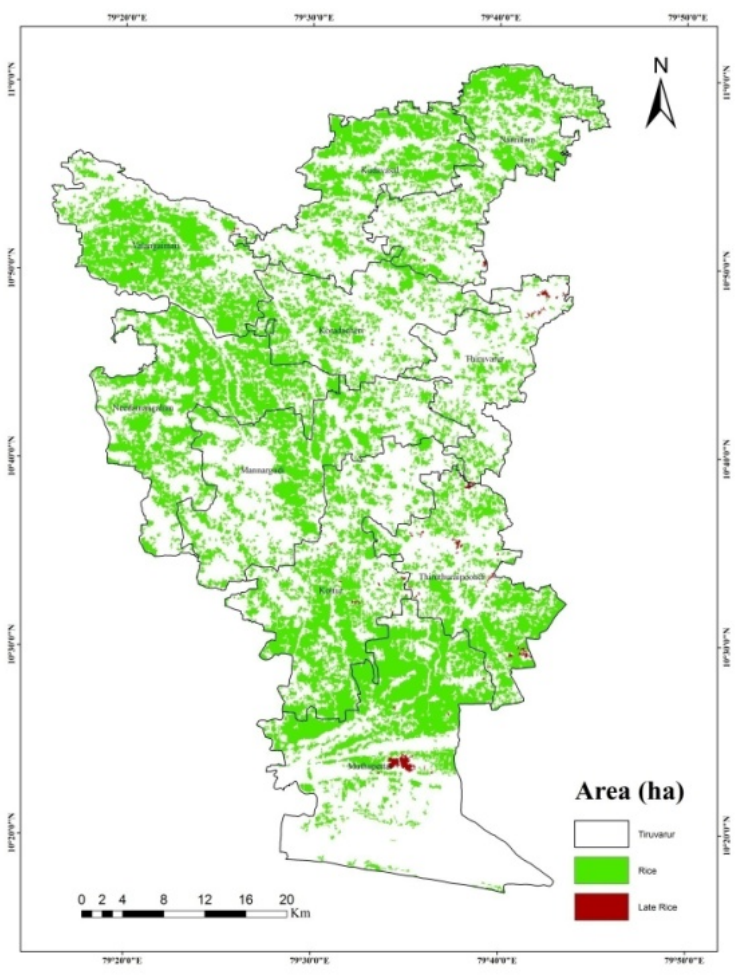

Fig.5 Rice Area Map of VV Polarization

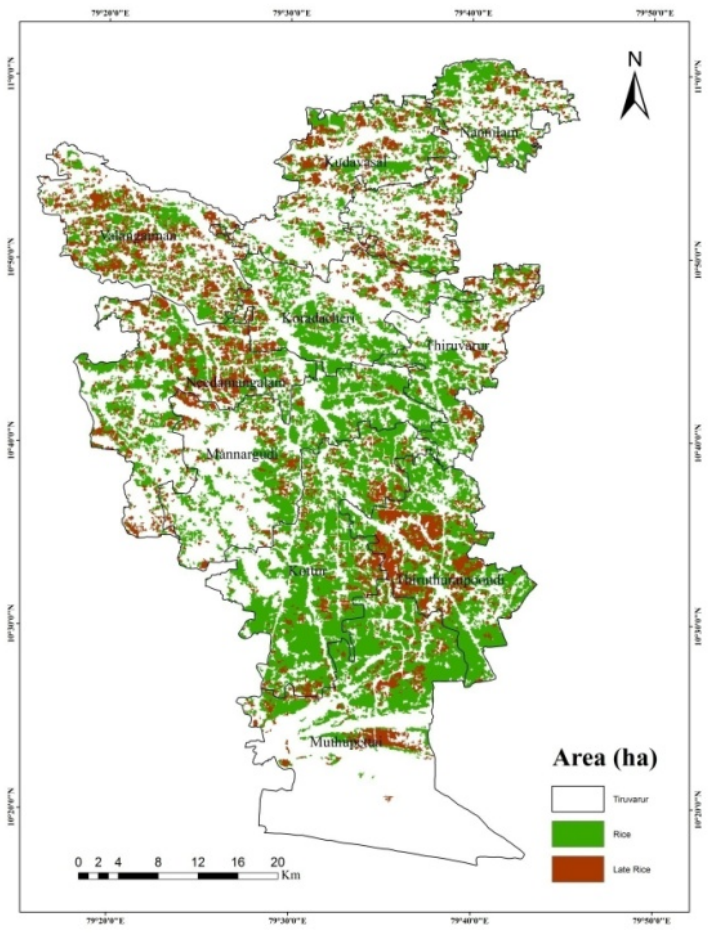

Fig.6 Rice Area Map of VH Polarization 


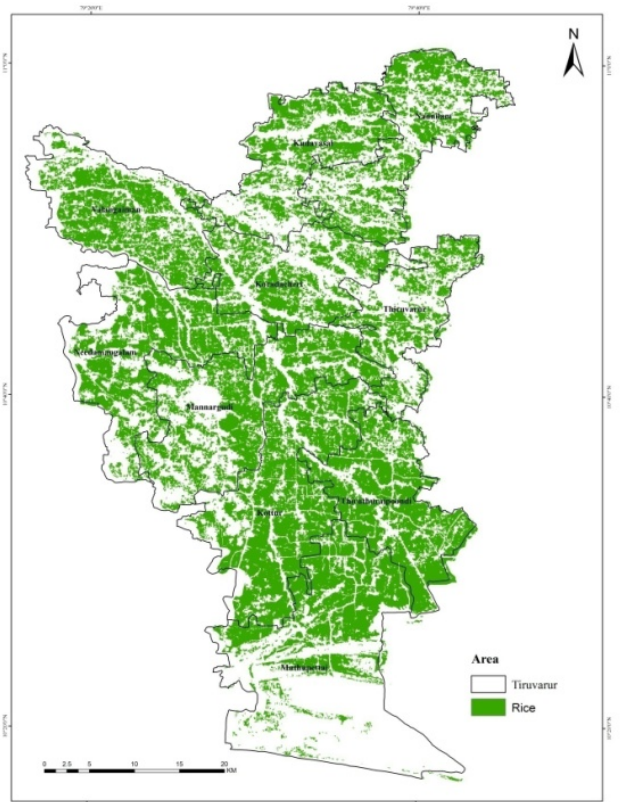

Fig.7 Rice Area Map of Integrated VV-VH Polarization

\begin{tabular}{|l|l|l|l|}
\hline NAME & \multicolumn{1}{|c|}{$\begin{array}{c}\text { VV Rice } \\
\text { area }\end{array}$} & $\begin{array}{c}\text { VH Rice } \\
\text { area }\end{array}$ & $\begin{array}{c}\text { Integr } \\
\text { ated } \\
\text { Rice } \\
\text { area }\end{array}$ \\
\hline Nannilam & 8508 & 8103 & 10073 \\
\hline Kudavasal & 7931 & 8246 & 9421 \\
\hline Valangaiman & 9596 & 10178 & 11518 \\
\hline Koradacheri & 8096 & 5798 & 9070 \\
\hline Tiruvarur & 6625 & 2880 & 6559 \\
\hline Needamangalam & 11932 & 12730 & 15191 \\
\hline Mannargudi & 11305 & 9461 & 14571 \\
\hline Kottur & 17348 & 11895 & 18936 \\
\hline Thiruthuraipoondi & 13033 & 8298 & 13874 \\
\hline Muthupettai & 12399 & 13418 & 15299 \\
\hline Total & $\mathbf{1 0 6 7 7 3}$ & $\mathbf{9 1 0 0 7}$ & $\mathbf{1 2 4 5 5 1}$ \\
\hline
\end{tabular}

Table.5 Comparison of block wise rice area derived from VV,

VH and integrated VV-VH Polarization for Tiruvarur district

\begin{tabular}{|c|c|c|c|c|}
\hline \multirow{3}{*}{ 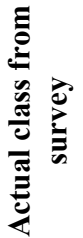 } & \multicolumn{4}{|c|}{ Predicted class from the map } \\
\hline & Class & Rice & $\begin{array}{l}\text { Non- } \\
\text { Rice }\end{array}$ & Accuracy \\
\hline & Rice & 71 & 23 & $75.5 \%$ \\
\hline
\end{tabular}

\begin{tabular}{|l|l|l|l|l|}
\hline \multirow{2}{*}{ Non-Rice } & 1 & 22 & $95.7 \%$ \\
\cline { 2 - 5 } & Reliability & $\mathbf{9 8 . 6 \%}$ & $\mathbf{4 8 . 9 \%}$ & $\mathbf{7 9 . 5 \%}$ \\
\hline
\end{tabular}

$85.6 \%$

Average accuracy

$\begin{array}{ll}\text { Average reliability } & 73.8 \% \\ \text { Overall accuracy } & 79.5 \% \\ \text { Kappa index } & 0.59\end{array}$

Table.6 Confusion matrix for accuracy assessment of rice classification for VV polarization

\begin{tabular}{|c|c|c|c|c|}
\hline \multirow{5}{*}{ 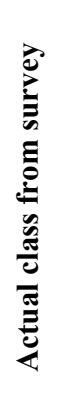 } & \multicolumn{4}{|c|}{ Predicted class from the map } \\
\hline & Class & Rice & $\begin{array}{l}\text { Non- } \\
\text { Rice }\end{array}$ & Accuracy \\
\hline & Rice & 74 & 20 & $78.7 \%$ \\
\hline & Non-Rice & 1 & 22 & $95.7 \%$ \\
\hline & Reliability & $98.7 \%$ & $52.4 \%$ & $82.1 \%$ \\
\hline
\end{tabular}

$\begin{array}{lr}\text { Average accuracy } & 87.2 \% \\ \text { Average reliability } & 75.5 \% \\ \text { Overall accuracy } & 82.1 \% \\ \text { Kappa index } & 0.64\end{array}$

Table.7 Confusion matrix for accuracy assessment of rice classification for $\mathrm{VH}$ polarization

\begin{tabular}{|l|l|l|l|l|}
\hline & Non-Rice & 4 & 19 & $82.6 \%$ \\
\hline & Reliability & $\mathbf{9 5 . 7 \%}$ & $\mathbf{7 6 . 0} \%$ & $\mathbf{9 1 . 5 \%}$ \\
\hline
\end{tabular}

$88.1 \%$

Average accuracy

Average reliability $\quad 85.8 \%$

Overall accuracy $\quad 91.5 \%$

Kappa index $\quad 0.83$

Table. 8 Confusion matrix for accuracy assessment of rice classification for Integrated VV-VH polarization 


\section{REFERENCES}

De Zan, F. and A. M. Guarnieri. 2006. TOPSAR: Terrain Observation by Progressive Scans. IEEE Transactions on Geoscience and Remote Sensing, 44(9), pp. 2352-2360.

Holecz, F., M.F.L. Barbieri, A. Collivignarelli, T.D.M. Gatti, Nelson, G. Setiyono, Boschetti, P.A.B. Manfron, J.E. Quilang. 2013. An operational remote sensing based service for rice production estimation at national scale. In: Proceedings of the Living Planet Symposium, Edinburgh, UK, pp. 9-11.
Congalton, R.C. 1991. A review of assessing the accuracy of classifications of remotely sensed data. Remote Sensing Environment, 37, pp. 35-46.

Richards, J.A. 1993. Remote Sensing Digital Image Analysis. Springer, Heidelberg, New York.*

Karjalainen, M., H. Kaartinen, J. Hyyppa, H. Laurila and R. Kuittinen. 2004. The Use of ENVISAT Alternating Polarization SAR Images in Agricultural Monitoring in Comparison with RADARSAT-1 SAR Images 